\title{
PELATIHAN PERTANIAN HIDROPONIK MODERN BAGI KELOMPOK PKK DESA TABA PADANG REJANG
}

\footnotetext{
${ }^{1}$ Ardiwijaya, ${ }^{2}$ Supriatin, ${ }^{3}$ Agus Setiawan, ${ }^{4}$ Deki Rahmat, ${ }^{5}$ Merti Sri Hariani, ${ }^{6}$ Meny Avida, ${ }^{7}$ Nur'aini ${ }^{1,2,3,4,5,6,7)}$ Program Studi Teknik Informatika, Fakultas Teknik, Universitas Muhammadiyah Bengkulu Coresponden Author : ardiwijaya@umb.ac.id
}

Informasi Artikel

Terima : 31/03/2021

Revisi : 04/07/2021

Disetujui : 02/08/2021

Kata Kunci:

pelatihan, hidroponik

,desa taba padang

rejang

\section{ABSTRAK}

Pelatihan pertanian hidroponik kepada masyarakat ini bertujuan untuk meningkatkan kemampuan masyarakat dalam mengembangkan pertanian melalui pertanian hidroponik sehingga menghasilkan sayuran yang sehat, meningkatkan perekonomian dalam kebutuhan sehari-hari dan sebagai temat wisata di desa tersebut. Berdasarkan survey dan analisis situasi yang telah dilakukan maka dapat diidentifikasi permasalahan sebagai berikut: 1) Rendahnya pengetahuan tentang teknik budidaya sayur sederhana dengan menggunakan sistem hidroponik modern, 2) Belum ada sosialisasi tentang teknik budidaya sayur secara hidroponik, 3) Masih kurangnya pemahaman masyarakat tentang pemanfaatan lahan sempit yang dapat dijadikan lahan sayur hidroponik modern, dan 4) untuk memaksimalkan potensi-potensi yang dimiliki oleh suatu desa guna meningkatkan kesejahteraan masyarakatnya. Demi mencapai tujuan tersebuat adapun tahapan yang dilakukan sebagai berikut: 1) pelatiahan dan pemberian materi tentang hidroponik, 2) Pelatihan dan Praktik Pembuatan system hidroponik, 3) Pelatihan dan Praktik Pembuatan wadah hidroponik, 4) Pendampingan dan praktik berkebun dengan system hidroponik serta 5) Pendampingan dan praktik perawatan hingga masa panen. Dari Hasil pelatihan tersebut yang akan terbentuknya kebun hidroponik, agrowisata, agromart, tempat edukasi hidroponik, dan menjadi suatu desa percontohan hidroponik. hasil tersebut yang akan dikelola bersama Kelompok Ibu-ibu PKK dan masyarakat desa taba padang rejang,kecamatan hulu palik,kabupaten bengkulu utara. Menjadikan peran masyarakat yang lebih baik terkait dengan pengembangan kegiatan pertanian hidroponik, sehigga program pertanian hidroponik tersebut akan terus berkelanjutan.
PENDAHULUAN

Pelatihan pertanian hidroponik terhadap masyarakat desa merupakan upaya untuk mengembangkan kemandirian dan kesejahteraan masyarakat dengan meningkatkan pengetahuan, sikap, keterampilan, perilaku, kemampuan, kesadaran, serta memanfaatkan sumber daya melalui penetapan kebijakan, program, 
kegiatan, dan pendampingan yang sesuai dengan esensi masalah dan prioritas kebutuhan masyarakat desa taba padang rejang kecamatan hulu palik kabupaten bengkulu utara.

Pelatiahan pertanian hidroponik bertujuan untuk membangun desa dalam melakukan sosialisasi bersama sebagai suatu kesatuan yang melibatkan berbagai kalangan kepentingan ditingkat pemerintah desa, masyarakat desa, maupun pihak lain untuk mendorong partisipasi dan mendayagunakan kemampuan masyarakat desa dalam proses pembangunan desa, menyusun perencanaan pembangunan yang berpihak pada kelompok miskin, serta meningkatkan kapasitas dan kualitas sumberdaya manusia di desa taba padang rejang kecamatan hulu palik kabupaten bengkulu utara.

Dalam pertanian hidroponik ini bisa dilakukan diberbagai tempat yaitu baik di desa, di perkotaan, di lahan terbuka, atau diatas apartemen. Luas tanah yang sempit, kondisi tanah keritis, hama dan penyakit yang terkendali, keterbatasan jumlah air irigasi, musim yang tidak menentu, dapat ditanggulangi dengan system hidroponik ini. Budidaya hidroponik dapat diusahakan sepanjang tahun. Oleh karena itu harga jualnya tidak akan jatuh. Pemeliharaannya lebih muda karena tempat budidayanya relatif bersih, media tanamnya steril, tanaman terlindungi dari terpaan hujan, serangan hama dan penyakit relatif kecil, serta tanaman lebih sehat dan produkstivitas tanaman lebih tinggi (Sarido, L \& Junia 2017)

Hidroponik berkembang karena banyak kelebihan yaitu: tanpa menggunakan tanah, air tetap berada dalam system dan dapat dipergunakan kembali, tingkatan nutrient dapat diatur sesuai kebutuhan tanaman, tidak menyebabkan polusi nutrisi dalam system lingkungan, berdaya hasil tinggi, dan penyakit serta hama dapat dengan mudah untuk ditanggulangi sehingga tampa takut resiko gagal panen (Sastro, Y. \& Nofi A. R, 2016).

Dalam mengunakan system hidroponik ini dapat memberikan suatu lingkungan pertumbuhan yang lebih terkontrol. Penggunaan sistem hidroponik tidak mengenal musim dan tidak memerlukan lahan yang luas dibandingkan dengan kultur tanah untuk menghasilkan satuan produktivitas yang sama, sehingga dalam penerapan pertanian hidrponik ini bisa

dimana lakukan saja (Lonardy, 2006). 
Sampai saat ini tanaman yang paling sering dibudidayakan dengan system hidroponik adalah tanaman sayuran daun salah satunya adalah pakcoy. Tanaman pakcoy (Brassica rapa L) merupakan salah satu tanaman yang mudah ditanam dan ekonomis. Tanaman ini dapat tumbuh di dataran tinggi dan dataran rendah, dalam system hidroponik tidak hanya sayuran saja dibudidyakan melainkan juga bisa membudidayakan buah-buahan dan obat-obatan (MEGSARI, Ria; ASMULIANI, R.,2020)

Hidroponik merupakan solusi di bidang pertanian dengan menggunakan teknologi sederhana untuk memudahkan masyarakat dalam bercocok tanam. Hidroponik mampu menghasilkan produksi tanaman yang lebih terjamin kebebasannya dari hama penyakit yang berasal dari tanah, dapat dijadikan profesi baru sebagai mata pencaharian bagi petani dan masyarakat desa taba padang rejang yang tidak memiliki pekerjaan, meningkatkan pemenuhan sumber gizi keluarga dan masyarakat, dan apabila diusahakan dalam skala besar dapat meningkatkan ekspor produksi hortikultura segar dan berkualitas tinggi sehingga dapat menambah pendapatan desa.
Hidroponik juga memiliki keuntungan bagi lingkungan sosial karena dapat dijadikan sarana pendidikan dan pelatihan di bidang pertanian modern mulai dari kanakkanak sampai dengan orang tua, memperindah lingkungan dengan kesan pertanian yang bersih dan sehat, dengan usaha tersebut dapat menghasilkan agrowisata,agribisnis, tempat edukasi hidroponik dan salah satu desa percontohan hidroponik yang di pedesaan tanpa mencemari lingkungan (MEGSARI, Ria; ASMULIANI, R. Uji,2020).

Tumbuhan yang dibudidaya secara hidroponik tumbuh dua kali lebih cepat dibandingkan dengan sistem konvensional. Hal ini disebabkan kontak langsung antara akar dengan oksigen, tingkat keasaman yang optimum, serta adanya peningkatan penyerapan nutrien dan nutrisi yang seimbang menjadikan tanaman tubuh dengan subur (Wahome et al. 2011).

\section{METODE PELAKSANAAN \\ KEGIATAN}

Metode pelaksanaan kiagiatan ini terdiri dari beberapa tahapan yang perlu dilakukan mulai dari perencanaan, pengusulan hingga pelaporan dalam serangkaian kegiatan pelaksanaan 
pelatihan kepada masyarakat. Metode pelaksanaan dalam kegiatan pengabdian kepada masyarakat ini diawali dengan melakukan survey lokasi di desa taba padang rejang, kecamatan holu palik,kabupaten bengkulu utara,provinsi bengkulu oleh tim pengusul sehingga terjalinya kerja sama antara kepala desa, ibu-ibu pkk, dan masyarakat daam melaksanakan pelatihan tersebut. (Sutrisno; Sunarsi, Denok,2019).

Adapun tahapan pelaksanaan program Untuk mencapai target luaran yang telah direncanakan, pelatiahan kepada ibu-ibu pkk dan masyarakat ini dilakukan melalui beberapa tahapan yaitu sebagai berikut:

\section{Perencanaan}

Perencanaan ini terdiri survie yang dilakukan, identifikasi kebutuhan masyarakat, kerjasama oleh pihak masyarakat tujuan dan kesepakatan oleh desa tujuan.

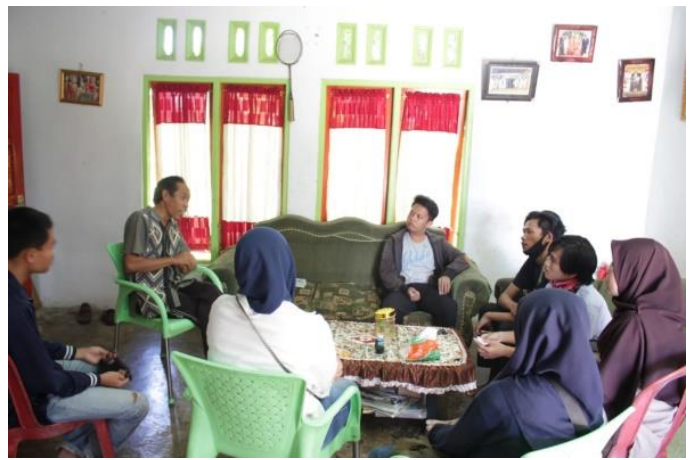

Gambar 2.1. perencanaan

\section{Pengusulan}

Pengusulan ini dilakukan oleh mahasiswa ke kemendikbud dengan program PHP2D(program holistik pembinaan dan pemberdayaan desa) dari pengusulan proposal maka adanya bantuan pendanaan untuk program pelatihan tersebut, sehingga akan berjalan sesuai apa yang ingin dicapai.

\subsection{Lokasi Kegiatan}

Kegiatan pelatihan ini berlokasi di Desa taba padang rejang, Kecamatan hulu palik, Kabupaten Bengkulu utara, Provinsi bengkulu. Kegiatan dilaksanakan bulan september november 2020.

\section{Partisipan Kegiatan}

Khalayak sasaran adalah Tim Penggerak PKK Desa taba padang rejang beserta masyarakat Kecamatan hulu palik, Kabupaten Bengkulu utara. Masyarakat Desa taba padang rejang. (Sesanti, Rizka Novi; User, Sismanto.,2019)

\section{Menetapkan Tujuan}

Dalam menetapkan tujuan, pelatihan menyampaikan tujuan yang akan dicapai dalam kegiatan pelatiahan kepada masyarakat. Sehingga dalam pelaksanaan pelatiahan kepada masyarakat terstruktur dan terarah 
tentang tujuan yang akan dicapai.

Pelatiahan meminta kerjasama yang baik kepada kepala desa dan mitra-mitra yang dijadikan sasaran.

\section{Menyusun Materi}

Dalam menyusun materi tim menyiapkan beberapa materi yaitu bagaimana pembuatan tanaman hidroponik dengan benar, bagaimana media yang digunakan dan sampai pada pelaksanaan kegiatan praktek cara bercocok tanam dengan menggunakan system hidroponik.

\section{Praktik system penyemaian}

\section{hidroponik}
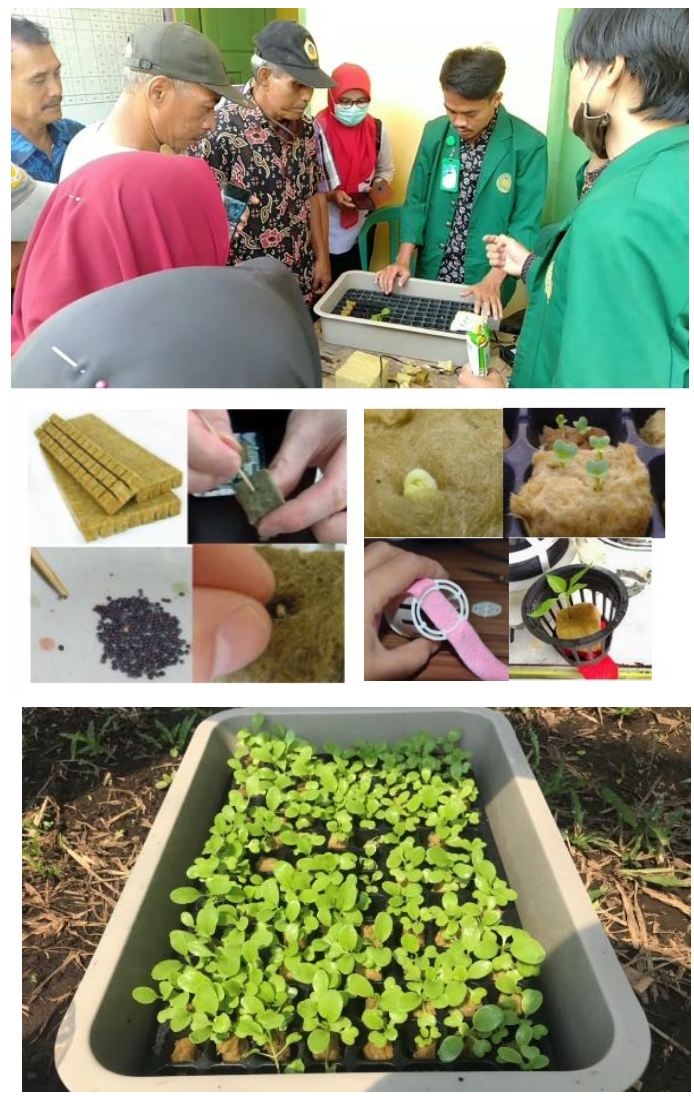

Gambar 2.7.penyemaian
Dalam pelatihan ini menjelaskan dari pembibitan awal dengan bahan bahan sebagai berikut :

1) Benih tanaman (buah-buahan atau sayuran. Contoh buah-buahan yaitu stoberi, tomat, paprika. Contoh sayuran yaitu pakcoy, kangkung, bayam dan selada)

2) Netpot (wadah untuk tanaman)

3) Rockwool (media tanam yang bersifat menyerap dan menyimpan air)

4) Nutrisi (biasanya menggunakan nutrisi $\mathrm{AB}$ MIX untuk buah-buahan maupun sayuran)

5) Trey (wadah untuk proses pembibitan)

Penyemaian merukapan tahap awal dalam berkebun hidroponik, media yang digunakan yaitu rockwool. Cara menyemai yaitu sebagai berikut :

1) Media tanam rockwool dipotong kecil, diletakkan di atas wadah, dan dibasahi dengan air secukupnya agar basah

2) Pada rockwool dibuat lubang dengan menggunakan tusuk gigi untuk tempat bibit

3) Bibit tanaman dimasukkan ke dalam lubang dan wadah disimpan di dalam tempat gelap Untuk tanaman yang menjulang tinggi seperti sawi, bayam dan kangkung, 1 rockwool bisa diisi 2-3 
benih, tetapi untuk yang tumbuh kesamping seperti pakchoy dan selada cukup 1 benih saja. Untuk cabe dan tomat cukup 1-2 benih.

Kelembaban rockwool harus diperiksa secara berkala. Apabila kering, maka perlu ditambahkan air.

1) Setelah 1-4 hari, bibit akan pecah yang ditandai dengan warna putih. Lamanya pecah tergantung dari jenis tanaman

2) Jika benih tanaman sudah pecah, maka wadah ditempatkan di daerah yang terkena sinar matahari minimal 6 jam sehari

3) Setelah berdaun empat, tanaman dipindahkan ke instalasi hidroponik yang telah diberi nutrisi sesuai dengan konsentrasi yang dibutuhkan tanaman.

\section{Praktik pembuatan wadah}

\section{hidroponik}

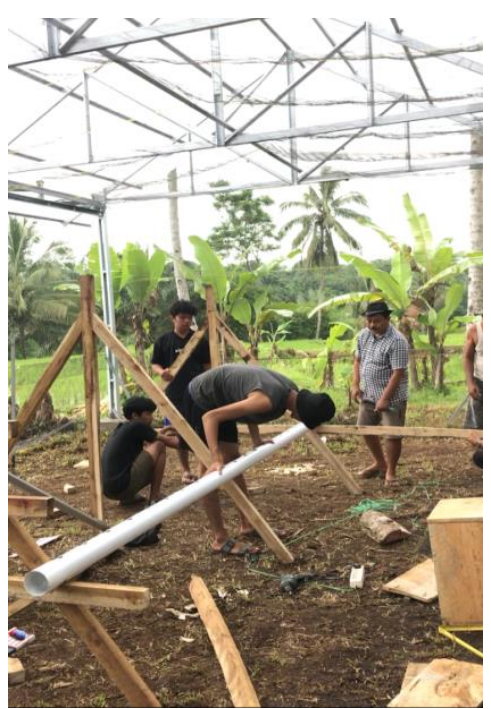

Gambar 2.8. Pembuatan Wadah
Seperti gamabar diatas Dalam pelatihan ini membuat suatu system wadah hidroponik sesudah masa semai, pelatiahan ini mengunakan metode nft(Nutrient Film Technique) yang bisa kita lihat hasil jadinya digambar dibawah ini

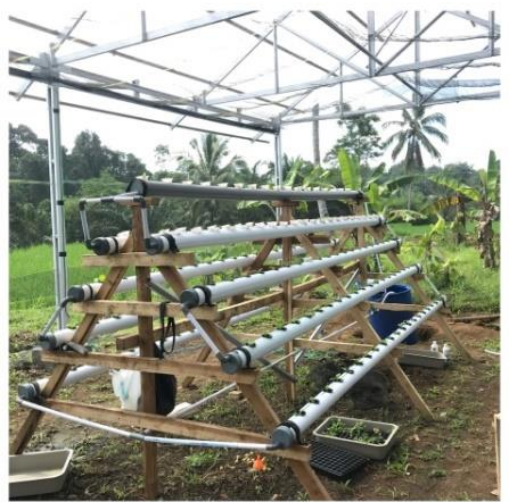

Gambar 2.9. Hasil

\section{Pendampingan dan praktik berkebun}

\section{hidroponik}

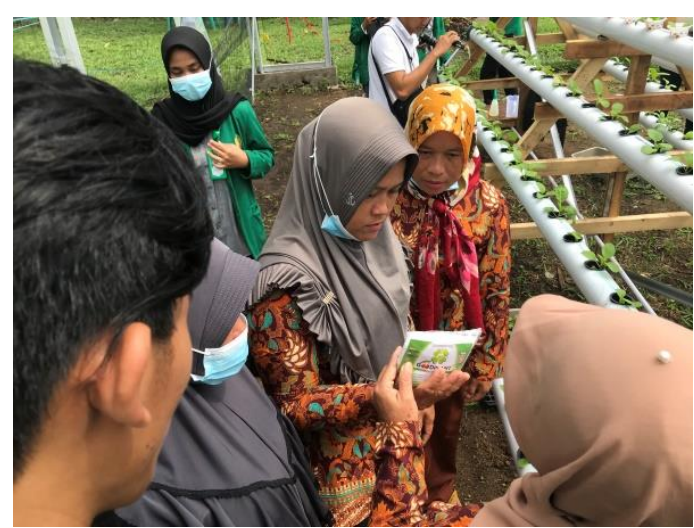

Gambar 2.10 Pendampingan

Dalam pendampingan ini, mepraktikan cara berkebun dengan hidroponik antara lain: 
1) Memberikan nutrisi secara berkalah terhadap tanaman.

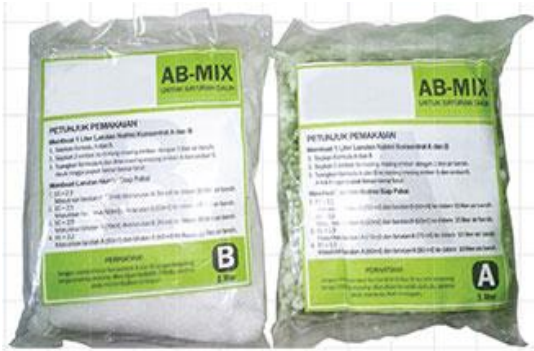

Gambar 2.11 Contoh Nutrisi AB MIX

Sistem hidroponik NFT adalah sistem hidroponik tanpa media tanam. Tanaman di tanam dalam sirkulasi hara tipis (film) pada talang hidroponik. Persemaian untuk sistem NFT dilakukan pada blok rockwool. Sirkulasi hara pada sistem ini diatur terus menerus, agar tanaman tidak kekurangan air dan nutrisi. Sistem hidroponik DFT menggunakan media tanam arang sekam yang diletakan di dalam pot kecil berlubang pada bagian bawah dan samping (net pot). Net pot tersebut kemudian diletakan pada talang yang dialiri nutrisi (Sesanti, Rizka Novi; User, Sismanto,2016).

2) mengecek kadar nutrisi dengan tds dan ph meter.

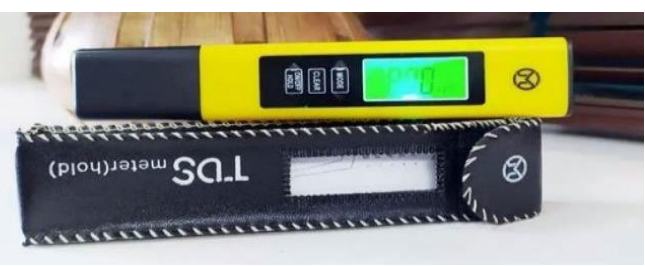

Gambar 2.12 TDS meter
3) Pemindahan benih tanam ke netpot.

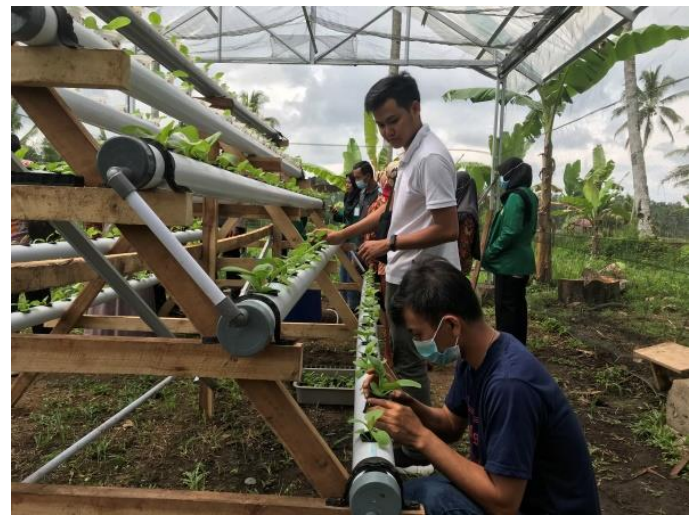

Gambar 2.13 Pemindahan Tanaman ke Netpot

\section{HASIL DAN PEMBAHASAN}

\section{Tahap serah terima hasil pelatiahan}

Pada tahap ini, menyerahkan paket hidroponik kepada kepala desa dan mitra desa untuk melanjutkan kegiatan ini selain menjadi desa percontohan hidroponik, tempat edukasi hidroponik, agromart,dan ini juga kedepanya akan bisa menjadi agrowisata didesa tersebut .

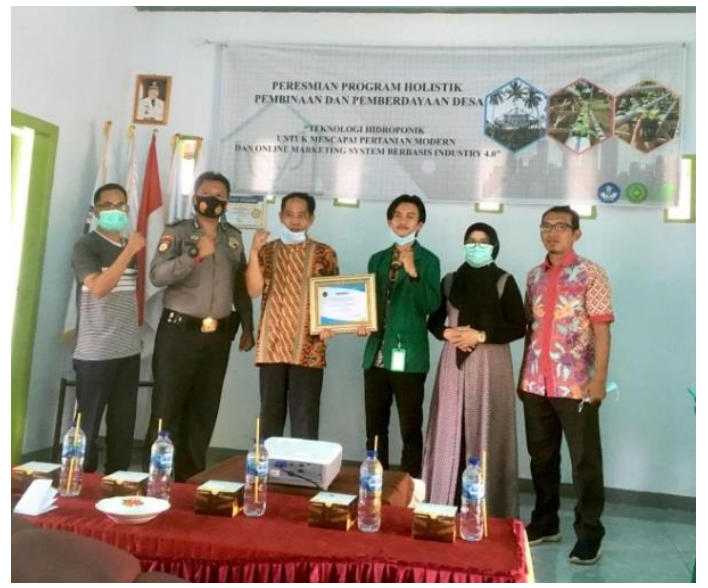

Gambar 3.1. Penyerahan piagam 


\section{Tahap presmian desa hidroponik}

Pada tahap ini, peresmian dilakukan dengan memong pita sebagai simbolis terhadap program yang sudah dilaksanakan didesa tab padang rejang.

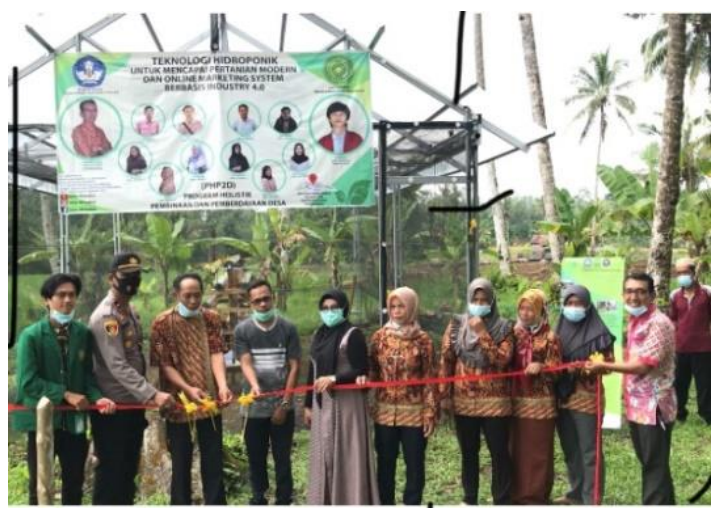

Gambar 3.2. Peresmian Hidroponik

Bersama Kelompok PKK

\section{Hasil Pertumbuhan}

Berikut ini adalah hasil dengan system teknologi hidroponik bisa dilihat dari foto :

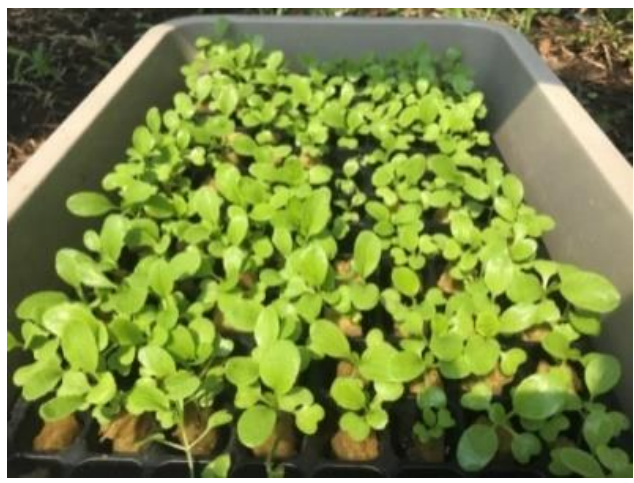

Gambar 3.3. Pakcoy Umur 12 hari

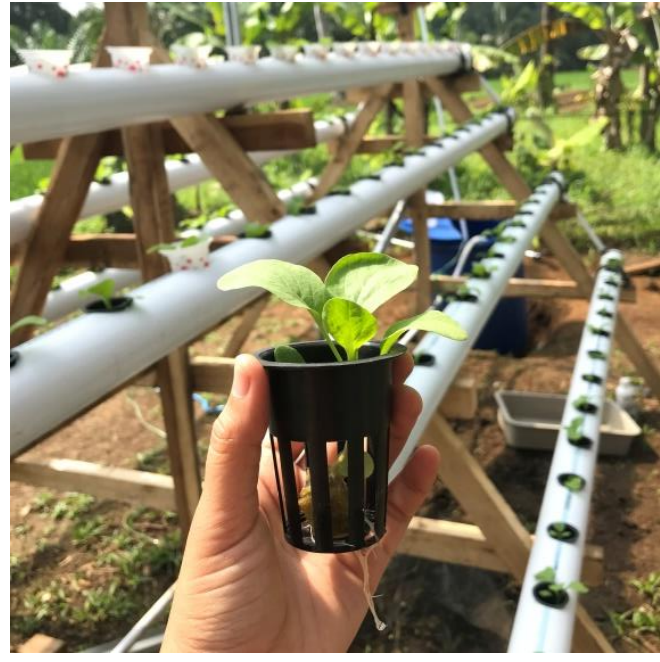

Gambar 3.4 Pakcoy umur 20 hari

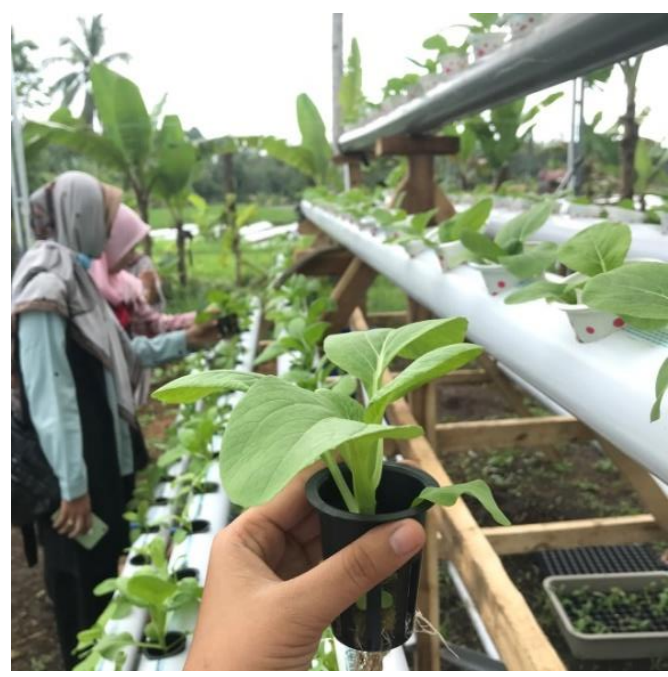

Gambar 3.5 Pakcoy umur 25 hari

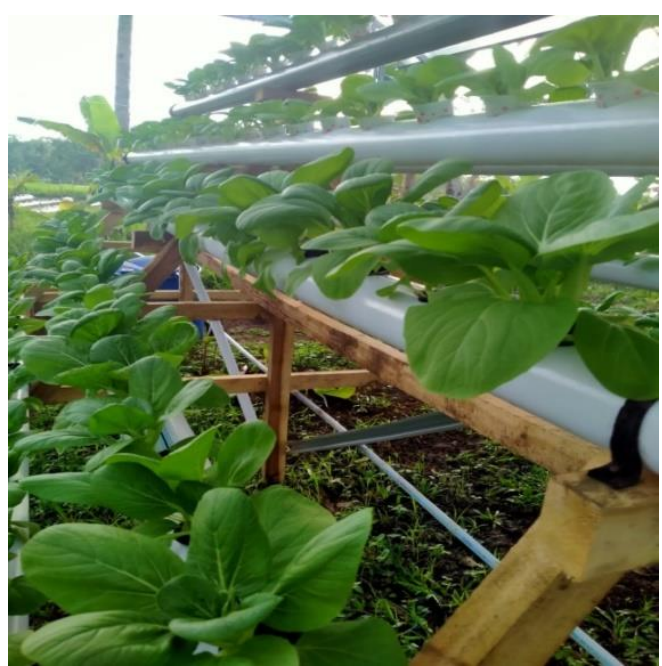

Gambar 3.6. Pakcoy umur 30 hari 


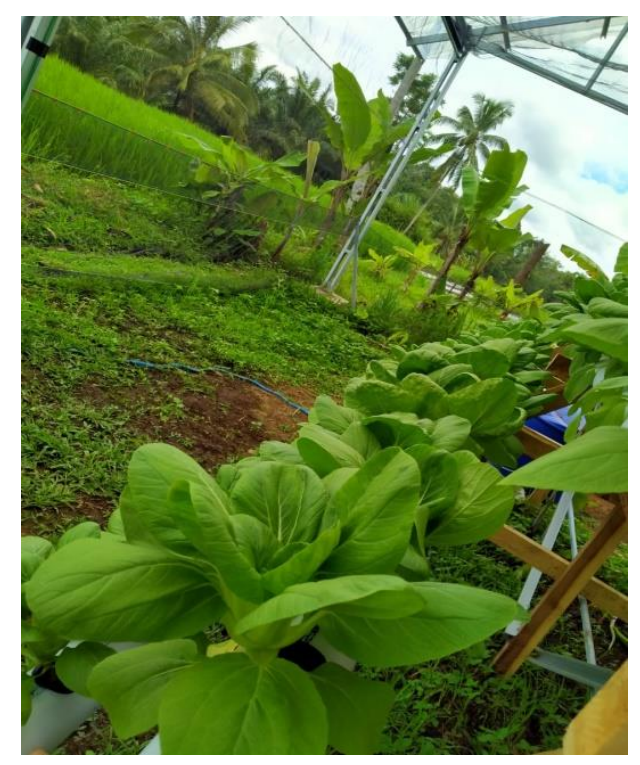

Gambar 3.7 Pakcoy Umur 32 hari

\section{KESIMPULAN}

Kegiatan pelatihan dan praktik pembuatan hidroponik telah dilaksanakan. Adapun hasil dari pengabdian ini adalah warga memahami cara bertanam dengan system hidroponik serta mampu mempraktekkannya. Hasil dari program ini terbentuk desa percontohan hidroponik,pusat edukasi hidroponik, agromart, dan agrowisata yang berada di desa taba padang rejang kecamatan hulu palik kabupaten bengkulu utara.

\section{DAFTAR PUSTAKA}

Sarido, La. Junia. 2017. Uji pertumbuhan dan hasil tanaman Pakcoy (Brassica rapa L.) dengan pemberian pupuk organik cair pada system hidroponik. Jurnal Agrifor, 16.1: 65-74.
Sastro, Yudi; Rokhmah, Novi A.; ASTUTI, Erna P. Efektivitas Kultur Campuran Bakteri Penambat n-bebas dan Pelarut Fosfat pada Tomat. 2016.

Lonardy, M. V. Respons tanaman tomat (Lycopersicon esculentum mill.) terhadap suplai senyawa nitrogen dari sumber berbeda pada sistem hidroponik. Skripsi"'(Tidak Dipublikasikan). Universitas Tadulako, Palu, 2006.

Megsari, Ria; Asmuliani, R. Uji Pertumbuhan Tanaman Pakcoy (Brassica rappa L) Dengan Pemberian Nutrisi Ab-Mix Dan Pupuk Organik Cair Pada System Hidroponik. Musamus Journal of Agrotechnology Research, 2020, 2.2: 45-51.

Mugundhan, R. M., et al. " Hydroponics"-a novel alternative for geoponic cultivation of medicinal plants and food crops. International Journal of Pharma and Bio Sciences, 2011, 2.2.

Wahome, Paul K., et al. Effects of different hydroponics systems and growing media on the vegetative growth, yield and cut flower quality of gypsophila (Gypsophila paniculata L.). World Journal of Agricultural Sciences, 2011, 7.6: 692-698.

Sutrisno, Sutrisno; SUNARSI, Denok. The Effect of Work Motivation and Discipline on Employee Productivity at PT. Anugerah Agung in Jakarta. Jurnal Ad'ministrare, 2019, 6.2: 187196. 
Mustikarini, Eries Dyah; Santi, Ratna; Inonu, Ismed. Pemberdayaan PKK Desa Pagarawan melalui Budi Daya Tanaman Sayuran dengan Sistem Hidroponik. Agrokreatif: Jurnal Ilmiah Pengabdian kepada Masyarakat, 2019, 5.3: 173-180.

Sesanti, Rizka Novi; USER, Sismanto. Pertumbuhan dan Hasil Pakchoi (Brasicca rapa L.) Pada Dua Sistem Hidroponik dan Empat Jenis Nutrisi. Inovasi Pembangunan: Jurnal Kelitbangan, 2016, 4.01: 1-9. 